\title{
Three new spider species of the genus Pholcus from the Taihang Mountains of China (Araneae, Pholcidae)
}

\author{
Bao-Shi Zhang ${ }^{1,2}$, Feng Zhang ${ }^{3}$, Jing-Ze Liu' \\ I College of Life Sciences, Hebei Normal University, Shijiazhuang, Hebei 050024, P. R. China 2 Department \\ of Biochemistry, Baoding University, Baoding, 071051, P. R. China 3 The Key Laboratory of Invertebrate \\ Systematics and Application, College of Life Sciences, Hebei University, Baoding, Hebei 071002, P. R. China \\ Corresponding author: Jing-Ze Liu (jzliu21@heinfo.net)
}

Academic editor: S. Li | Received 26 January 2016 | Accepted 20 April 2016 | Published 22 June 2016

http://zoobank.org/351C6930-61CC-4FB4-83BC-B712854BFFFO

Citation: Zhang B-S, Zhang F, Liu J-Z (2016) Three new spider species of the genus Pholcus from the Taihang Mountains of China (Araneae, Pholcidae). ZooKeys 600: 53-74. doi: 10.3897/zookeys.600.7924

\begin{abstract}
In this study, three new species belonging to the genus Pholcus, collected from a forest of the Taihang Mountains, P. R. China, are described under the names of Pholcus papillatus sp. n. (male, female), P. curvus sp. n. (male, female) and P. auricularis sp. n. (male, female).
\end{abstract}

\section{Keywords}

Hebei Province, Pholcinae, Pholcus phungiformes, species group, taxonomy

\section{Introduction}

The spider family Pholcidae C. L. Koch, 1850 is the ninth largest spider family and, to date, 1461 species, belonging to 79 genera, have been reported (World Spider Catalog 2016). It has a worldwide distribution, but the highest diversity is concentrated in the tropical and subtropical regions. Pholcine spiders occupy a wide range of habitats in a variety of ecosystems, e.g., in buildings, under rocks, in caves, in leaf litter, and under leaves (Huber 2005a). Huber (2000, 2001, 2003a, b, c, 2005b, c, 2009a, 2011b) reported a large number of new species and revised many genera in this family. Based on cladistic analyses of morphological and molecular data and on qualitative character assessment (Huber 2011a; Dimitrov et al. 2013), Pholcidae was divided into five 
subfamilies: Arteminae Simon, 1893, Modisiminae Simon, 1893, Ninetinae Simon, 1890, Pholcinae C.L. Koch, 1850 and Smeringopinae Simon, 1893; Pholcinae is the most species-rich subfamily.

Pholcus Walckenaer, 1805 is the largest genus in Pholcinae, with 318 described species which are mainly distributed in the Old World. Pholcus can be diagnosed by the following combination of characters: male chelicerae usually with three pairs of apophyses; bulb usually with uncus and appendix; epigynum usually strongly sclerotized and with 'knob' (Huber 2011b). These Pholcus spiders frequently live in houses, rock-crevices, caves and leaf litter, and most spin loose and irregular webs in sheltered areas. Recently, the genus has been studied by several scholars: Huber (2001) made a few taxonomic remarks; Dimitrov and Ribera (2007) and Dimitrov et al. (2008) revised and cladistically analyzed the Macaronesian Pholcus species; Zhang and Zhu (2009) reviewed 55 Chinese Pholcus species; Huber (2011b) revised the genus Pholcus and presented 254 species in 29 species groups; Yao and $\mathrm{Li}$ (2012) described 35 new species and also provided new illustrations for 45 known species from China and two species from Laos; Yao and Li (2013) described two new species from Laos; Yao, Pham and Li (2015) described five new species from Vietnam.

The spider genus Pholcus Walckenaer, 1805 exhibits a highly diversity in China. One hundred fifteen Pholcus species attached to nine species groups ( $P$. halabala species group, $P$. ponticus species group, $P$. crypticolens species group, $P$. zham species group, $P$. bidentatus species group, $P$. nagasakiensis species group, $P$. yichengicus species group, $P$. taishan species group, and $P$. phungiformes species group) were recorded from China (Zhang and Zhu 2009; Tong and Ji 2010; Tong and Li 2010; Huber 2011b; Peng and Zhang 2011a, b; Yao and Li 2012; Liu and Tong 2015; World Spider Catalog 2016).

The Taihang Mountains are located in the northeastern China, between $34^{\circ} 34^{\prime} \mathrm{N}$ to $40^{\circ} 43^{\prime} \mathrm{N}$ and $110^{\circ} 14^{\prime} \mathrm{E}$ to $114^{\circ} 33^{\prime} \mathrm{E}$. Fuping county, a county of Hebei Province, is located in the Taihang Mountains area. To explore the diversity of the arthropod in Fuping county, one survey was carried out in 2014. While examining the spider specimens collected from leaf litter in this survey, three new species belonging to Pholcus were found and are reported in the present paper. Detailed diagnosis, descriptions, and illustrations of these new taxa are presented.

\section{Material and methods}

All specimens were preserved in 75\% ethanol and examined, drawn, and measured under a Nikon SMZ1500 stereomicroscope equipped with a drawing tube. Photographs were taken with a Leica M205A stereomicroscope equipped with a Leica DFC550 Camera and LAS software (Ver. 4.6). Male and female genitalia were examined and illustrated after dissection. Epigyna were removed and treated in 10\% warm solution of potassium hydroxide $(\mathrm{KOH})$ before illustration. Left pedipalpi of male spiders were illustrated, except as otherwise indicated. All measurements are given in millimeters. Eye sizes were measured as the maximum diameter of the lens in dorsal or frontal view. Leg measurements are given as total length (femur + patella + tibia + metatarsus + 
tarsus). Leg segments were measured on their dorsal side. Terminology and taxonomic descriptions follow Huber (2000, 2009b).

The following abbreviations are used in the text:

$\begin{array}{ll}\text { AER } & \text { anterior eye row; } \\ \text { ALE } & \text { anterior lateral eye; } \\ \text { AME } & \text { anterior median eye; } \\ \text { MOA } & \text { median ocular area; } \\ \text { PER } & \text { posterior eye row; } \\ \text { PLE } & \text { posterior lateral eye; } \\ \text { PME } & \text { posterior median eye; } \\ \text { b } & \text { bulb; } \\ \text { e } & \text { embolus; } \\ \text { pa } & \text { pseudo-appendix; } \\ \text { pp } & \text { pore plate; } \\ \text { pr } & \text { procursus; } \\ \mathbf{u} & \text { uncus. }\end{array}$

All specimens used in this studied are deposited in the Museum of Hebei University, Baoding, P. R. China (MHBU).

\section{Taxonomy}

Family Pholcidae C. L. Koch, 1850

Genus Pholcus Walckenaer, 1805

Type species. Pholcus phalangioides (Fuesslin, 1775)

\section{Pholcus phungiformes species group}

The $P$. phungiformes group is largely distributed in northeastern China and the Korean Peninsula. Most species of this group have the following characters: carapace with vivid pattern, abdomen cylindrical, male chelicerae with proximal apophyses frontally, male palpal tibia with prolatero-ventral modification, procursus with dorsal spines, appendix absent, sometimes with pseudo-appendix (apophysis arising from uncus rather than from bulb, near usual position of appendix), epigynum sclerotized, with knobshaped apophysis (Huber 2011). The pseudo-appendix of P. exilis auct, date, P. wuling auct, date, and $P$. chicheng auct, date, may be bifid, but the character needs further study. The three new Pholcus species are assigned as members of this group in possessing most of the characters of the P. phungiformes group. 


\section{Pholcus papillatus sp. n.}

http://zoobank.org/3557D5D5-09B8-4733-BE13-767A8078CB1C

Figs $1-4$

Type material. Holotype: male (MHBU), CHINA: Hebei Province, Fuping County, Longquanguan Town, Liaodaobei Village, $38^{\circ} 16^{\prime} \mathrm{N}, 114^{\circ} 17^{\prime} \mathrm{E}$, alt. $1700 \mathrm{~m}, 6$ August 2014, B.S. Zhang leg. Paratypes: 1 male and 3 females (MHBU), same data as in holotype.

Etymology. The specific name is from Latin word "papillatus", in reference to the shape of epigynal apophysis; adjective.

Diagnosis. Narrow, long pseudo-appendix originating from the uncus (Fig. 2B). Distinguished from similar species with a pseudo-appendix by: palpal bulb with longer uncus, procursus with one spine-shaped projection and one hook-shaped membranous projection on tip (Figs 1A-D, 2A-B, 3A-D). The females of the new species are distinguished from females of similar species by the larger teat-shaped epigynal apophysis (Figs 2E, 4F).

Description. Male (holotype): Total length 4.90 ( 5.10 with clypeus), prosoma 1.40 long, 1.52 wide, opisthosoma 3.36 long, 1.68 wide. Habitus as in Fig. 4A-C. Dorsal shield of prosoma pale grey, with dark brown radiated stripes and bands marginally; thoracic groove distinct; ocular area elevated, with short eye-stalks; ocular area yellow-brown, with a median dark brown band and two lateral dark brown bands beside PLEs, dorsal prosoma and ocular area both with dispersed dark brown spots, of them, two distinct spots behind PMEs; clypeus 0.23 high, dark brown, with light margin. Diameter AME 0.08, ALE 0.13, PME 0.12, PLE 0.13. Distance AME-AME 0.07, AME-ALE 0.10, PME-PME 0.24, PME-PLE 0.04, ALE-ALE 0.62, PLE-PLE 0.78. MOA 0.23 long, front width 0.23, back width 0.46. Chelicerae as in Figs 2C-D and 4D-E, with pair of black apophyses distally, pair of unsclerotized, small and nearly nipple-shaped apophyses proximolaterally and frontally. Labium and endites dark brown, distal part pale, labium wider than long (0.32/0.15). Sternum wider than long (1.04/0.77), dark brown, median part of sternum light. Legs long, brown, but dark brown on proximal parts of tibiae, and on distal parts of femora and tibiae, with whitish on subdistal parts of femora and tibiae. Measurements of legs: I $36.78(9.59+0.59+9.69+15.43+1.48)$, II $26.81(7.37$ $+0.55+5.89+11.61+1.39)$, III $22.46(6.55+0.61+5.42+8.59+1.29)$, IV 24.58 $(7.06+0.53+5.74+9.89+1.36)$; tibia I L/d: 62 . Leg formula: 1243 . Opisthosoma pale grey, with dark spots dorsally and laterally. Pedipalpi illustrated in Figs 1A-D and 3A-D; trochanter with a long ventral apophysis; tibia with a small projection prolaterally; procursus simple proximally and complex distally, dorsal spines present; uncus with a pseudo-appendix, the tip of uncus long and bent; embolus weakly sclerotized.

Female. Generaly similar to male. One specimen measured: total length 4.58 (4.80 with clypeus), prosoma 1.34 long, 1.46 wide, opisthosoma 3.09 long, 1.44 wide. clypeus 0.23 high. Diameter AME 0.06, ALE 0.10, PME 0.09, PLE 0.11. Distance AME-AME 0.08, AME-ALE 0.07, PME-PME 0.19, PME-PLE 0.04, ALE-ALE 0.50, 

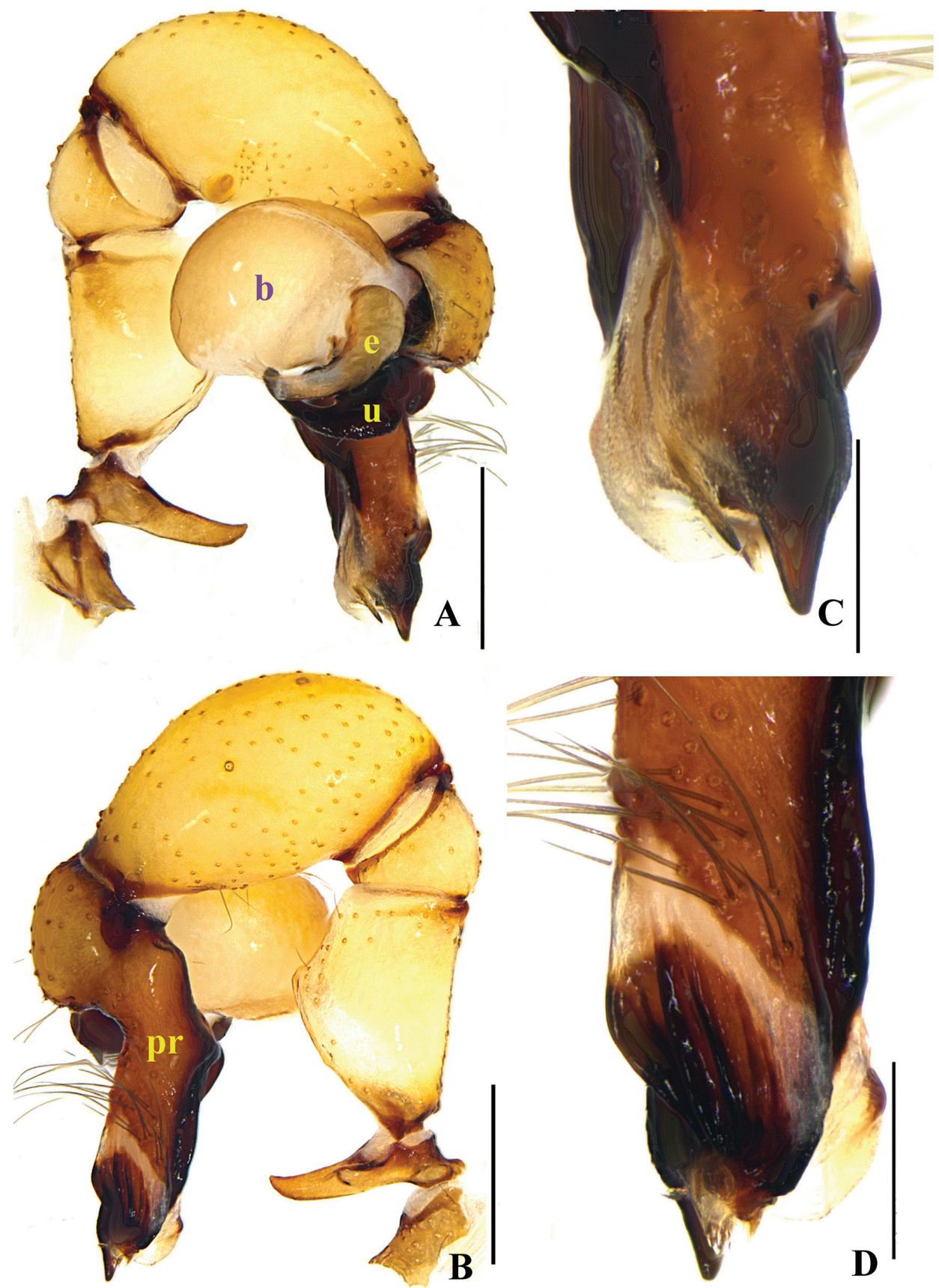

Figure I. Pholcus papillatus sp. n., male holotype. A-B Pedipalpus (A prolateral view B retrolateral view) C-D Distal part of procursus (C prolateral view $\mathbf{D}$ retrolateral view). Scale bars: $0.2 \mathrm{~mm}(\mathbf{C}, \mathbf{D})$; $0.5 \mathrm{~mm}(\mathbf{A}, \mathbf{B})$. 


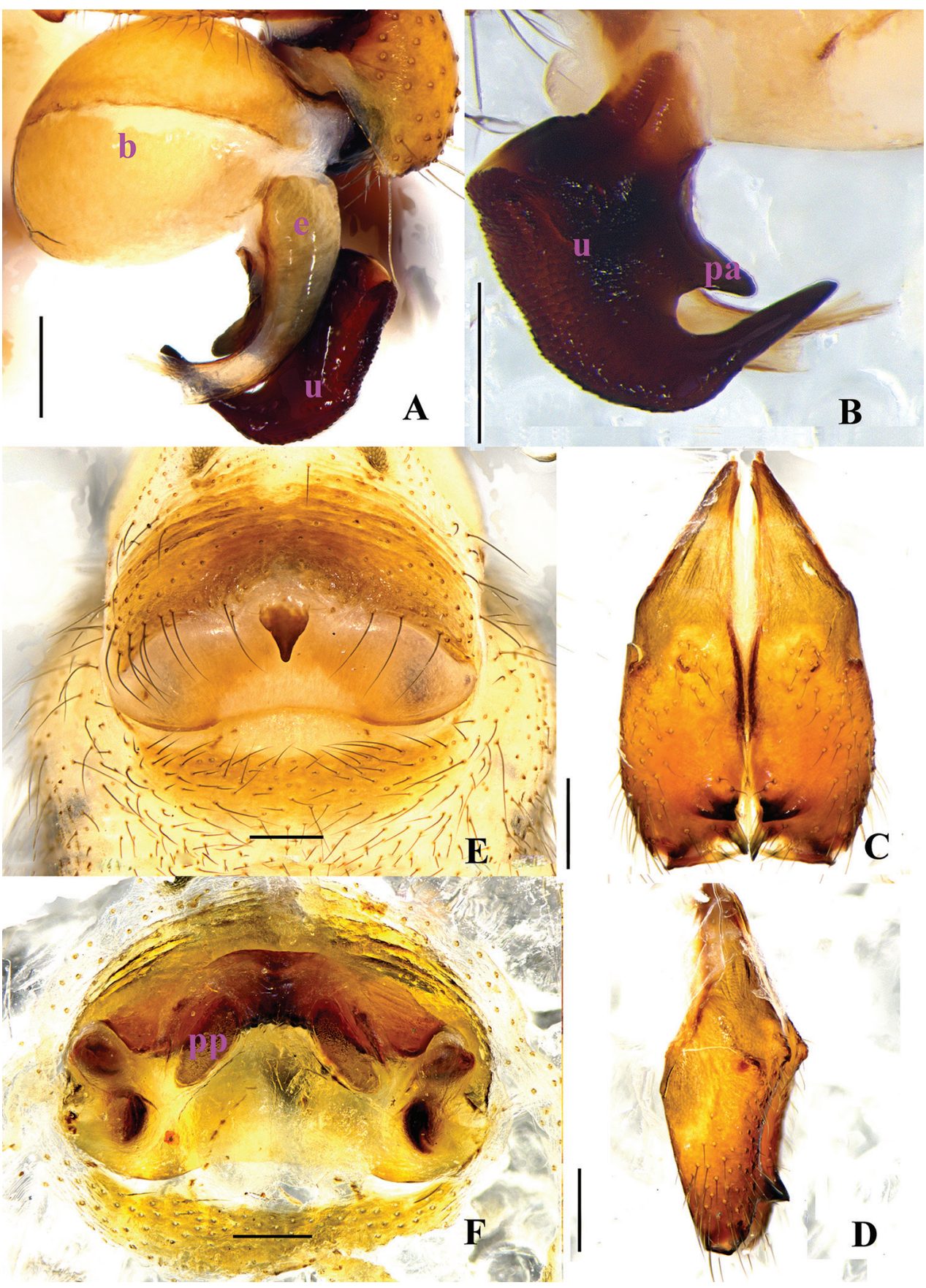

Figure 2. Pholcus papillatus sp. n., male holotype (A-D) and female paratype (E-F). A-B Bulb and uncus (A prolateral view $\mathbf{B}$ retrolateral view) C-D Chelicerae (C frontal view $\mathbf{D}$ lateral view) E Epigynum, ventral view F Vulva, dorsal view. Scale bars: $0.2 \mathrm{~mm}$. 

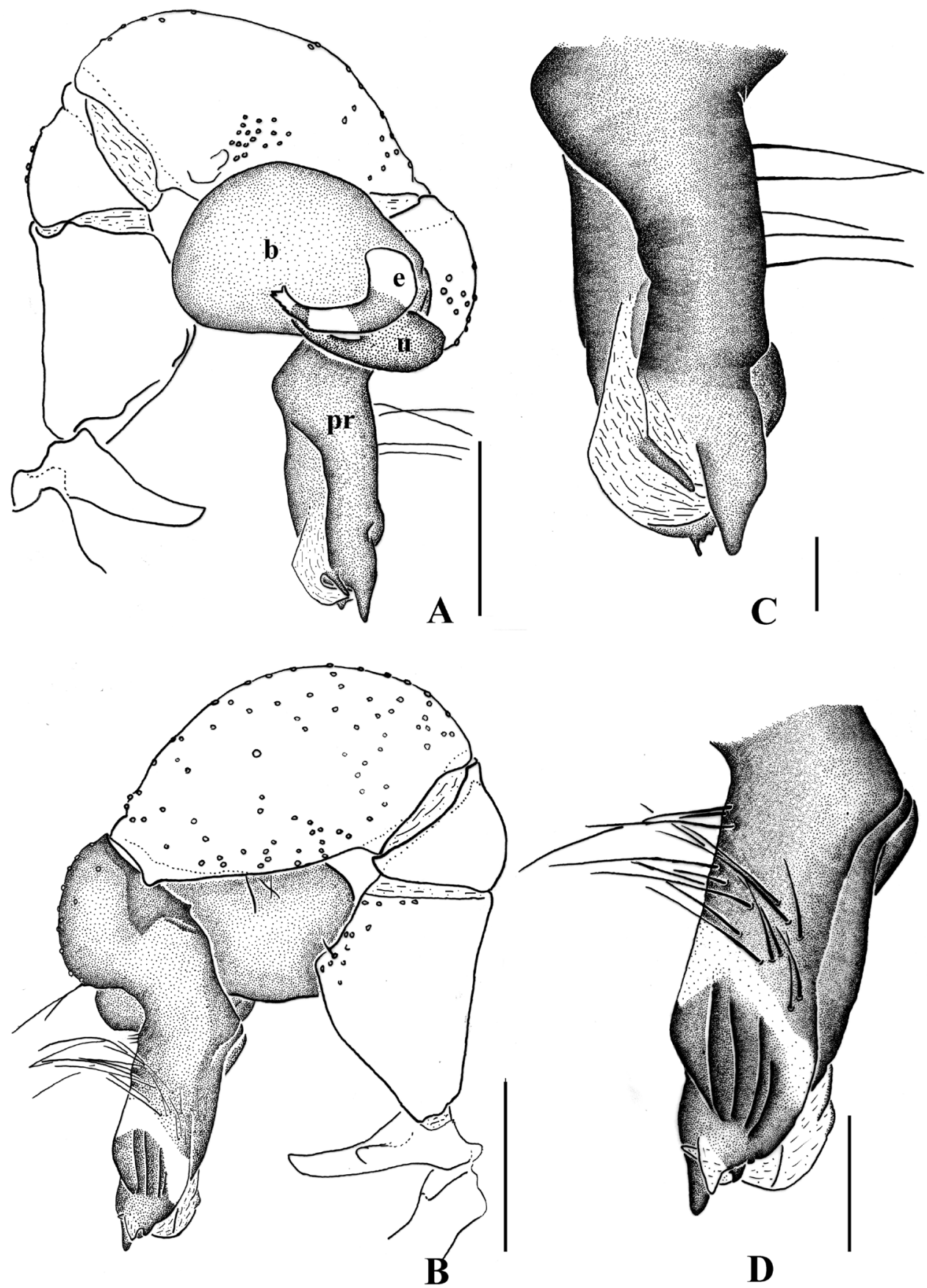

Figure 3. Pholcus papillatus sp. n., male holotype. A-B Pedipalpus (A prolateral view B retrolateral view) C-D Distal part of procursus (C prolateral view D retrolateral view). Scale bars: $0.2 \mathrm{~mm}$. 

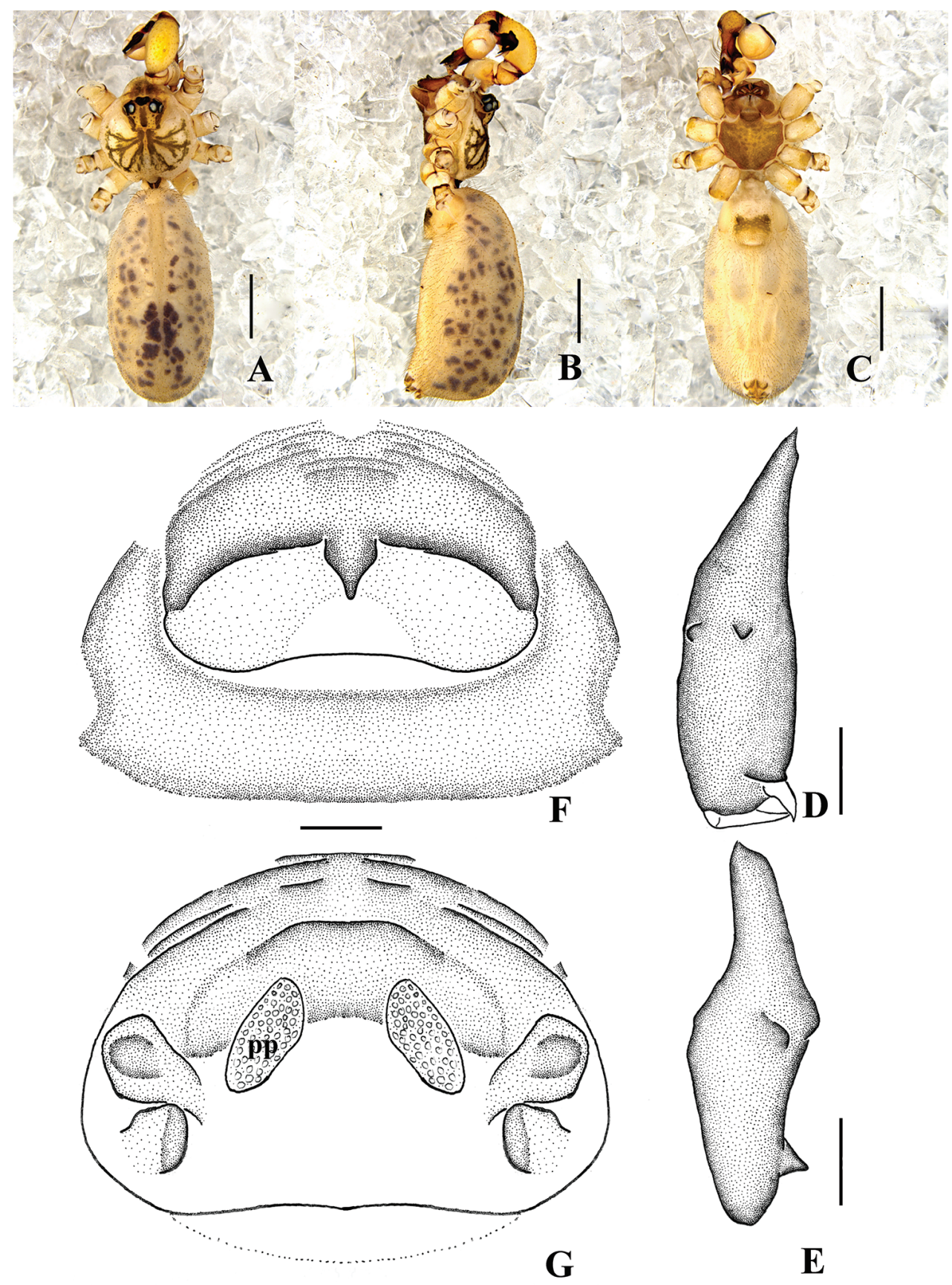

Figure 4. Pholcus papillatus sp. n., male holotype (A-E) and female paratype (F-G). A-C Habitus (A dorsal view B lateral view $\mathbf{C}$ ventral view) D-E Chelicerae (D, frontal view E lateral view) $\mathbf{F}$ Epigynum, ventral view G Vulva, dorsal view. Scale bars: $0.2 \mathrm{~mm}(\mathbf{D}-\mathbf{G}) ; 1.0 \mathrm{~mm}(\mathbf{A}-\mathbf{C})$. 
PLE-PLE 0.64. MOA 0.24 long, front width 0.18 , back width 0.39 . labium wider than long (0.31/0.18). Sternum wider than long (1.00/0.74). Measurements of legs: I $36.60(9.55+0.58+9.59+15.41+1.47)$, II $26.66(7.33+0.54+5.88+11.54+$ 1.37), III $22.32(6.51+0.58+5.38+8.58+1.27)$, IV $24.49(7.01+0.52+5.72+$ $9.88+1.36$ ); tibia I L/d: 60. Leg formula: 1243. Epigynum (Figs $2 \mathrm{E}$ and $4 \mathrm{~F}$ ) brown, roughly triangular, with distinct patterns and a teat-shaped apophysis on the top. Dorsal view of vulva (Figs $2 \mathrm{~F}$ and $4 \mathrm{G}$ ) with a rainbow-shaped, sclerotized arch anteriorly and two long ovoid pore plates, and a nearly meniscate sclerite.

Variation. Male: Total body length: 4.58, 4.90. Tibia I $(n=2): 8.96,9.59$ (mean: 9.28). Female: Total body length: 4.58, 4.63, 4.81. Tibia I $(n=3): 9.55,9.70,9.78$ (mean 9.68).

Distribution. Only known from the type locality.

Remarks. The females also resemble P. foliaceus Peng \& Zhang, 2013, but can be distinguished by the precurved margin of anterior plate of the epigynum and the long ovoid pore plates (Figs $2 \mathrm{E}-\mathrm{F}, 4 \mathrm{~F}-\mathrm{G}$ ).

\section{Pholcus curvus sp. $\mathrm{n}$.}

http://zoobank.org/81E106FA-EB6F-4ACB-89E8-1ECD43AD0E3C Figs $5-8$

Type material. Holotype: male (MHBU), CHINA: Hebei Province, Fuping County, Longquanguan Town, Heiyagou Village, $38^{\circ} 16^{\prime} \mathrm{N}, 114^{\circ} 05^{\prime} \mathrm{E}$, alt. $900 \mathrm{~m}, 5$ August 2014, B.S. Zhang leg. Paratypes: 2 males and 8 females (MHBU), same data as in holotype.

Etymology. The specific name is from the Latin word "curvus", in reference to the shape of the palpal uncus; adjective.

Diagnosis. Distinguished by the S-shaped tip of uncus, the long and curve beakshaped tip of the procursus, the hat-shaped membranous projection near tip, the small and almost quadrate-shaped epigynal apophysis (Figs 5A-D, 7A-D, 6E, 8F).

Description. Male (holotype): Total length 4.50 (4.63 with clypeus), prosoma 1.36 long, 1.41 wide, opisthosoma 2.85 long, 1.24 wide. Habitus as in Fig. 8A-C. Dorsal shield of prosoma pale grey, with brown radiated stripes and bands marginally; thoracic groove distinct; ocular area elevated, with short eye-stalks; ocular area yellowbrown, with a median brown band and two lateral brown bands beside PLEs, dorsal prosoma and ocular area both with dispersed brown spots, of them, two distinct spots behind PMEs; clypeus 0.20 high, brown. Diameter AME 0.07, ALE 0.08, PME 0.15, PLE 0.13. Distance AME-AME 0.06, AME-ALE 0.05, PME-PME 0.24, PME-PLE 0.06, ALE-ALE 0.49, PLE-PLE 0.62. MOA 0.24 long, front width 0.22 , back width 0.42. Chelicerae as in Figs 6C-D and 8D-E, with pair of black apophyses, pair of unsclerotized thumb-shaped apophyses proximolaterally, and pair of nearly long fingershaped apophyses frontally. Labium and endites brown, distal part pale, labium wider than long $(0.32 / 0.17)$. Sternum wider than long $(1.00 / 0.72)$, brown, median part of 


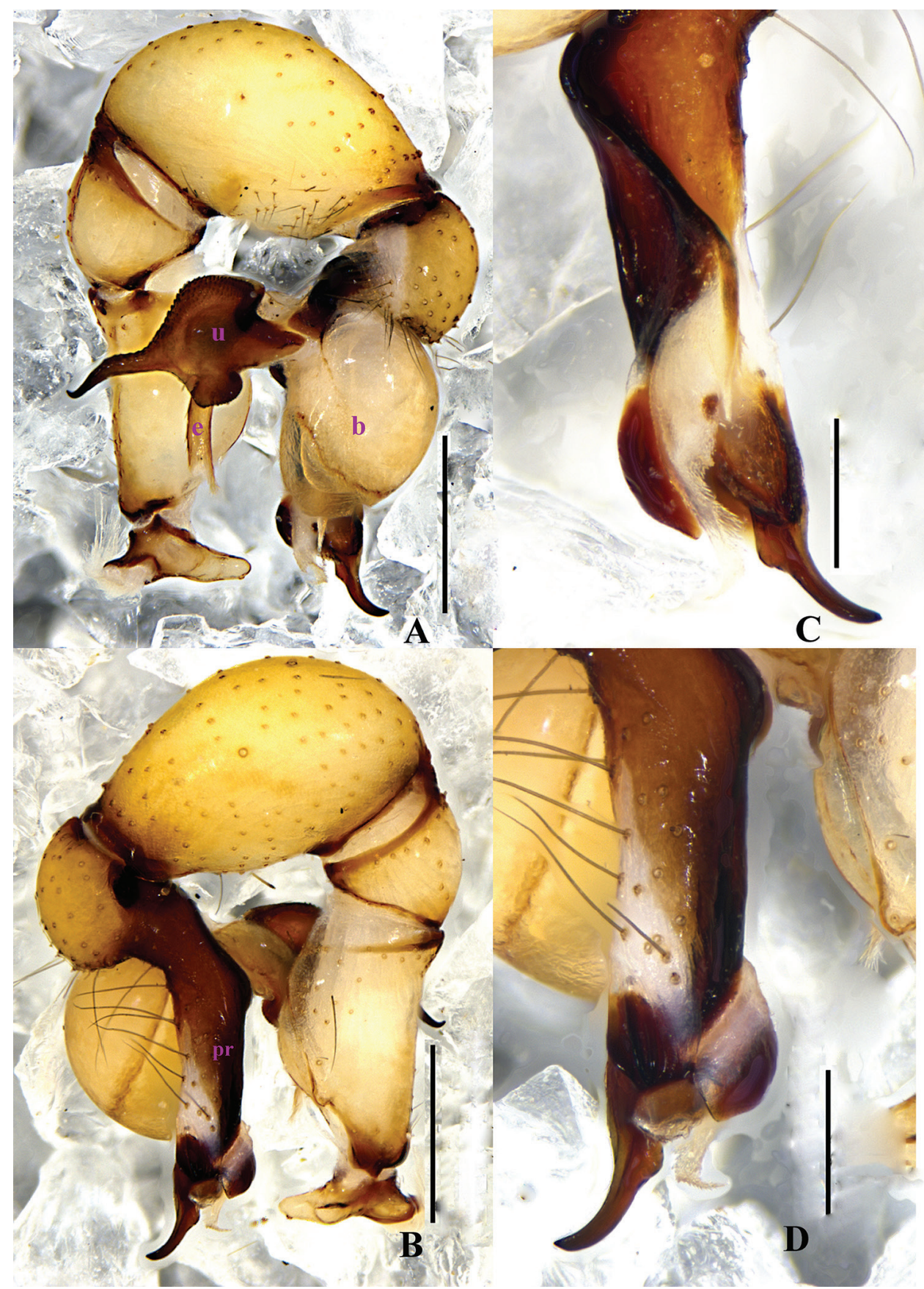

Figure 5. Pholcus curvus sp. n., male holotype. A-B Pedipalpus (A prolateral view B retrolateral view) C-D Distal part of procursus (C prolateral view D retrolateral view). Scale bars: $0.2 \mathrm{~mm}$. 


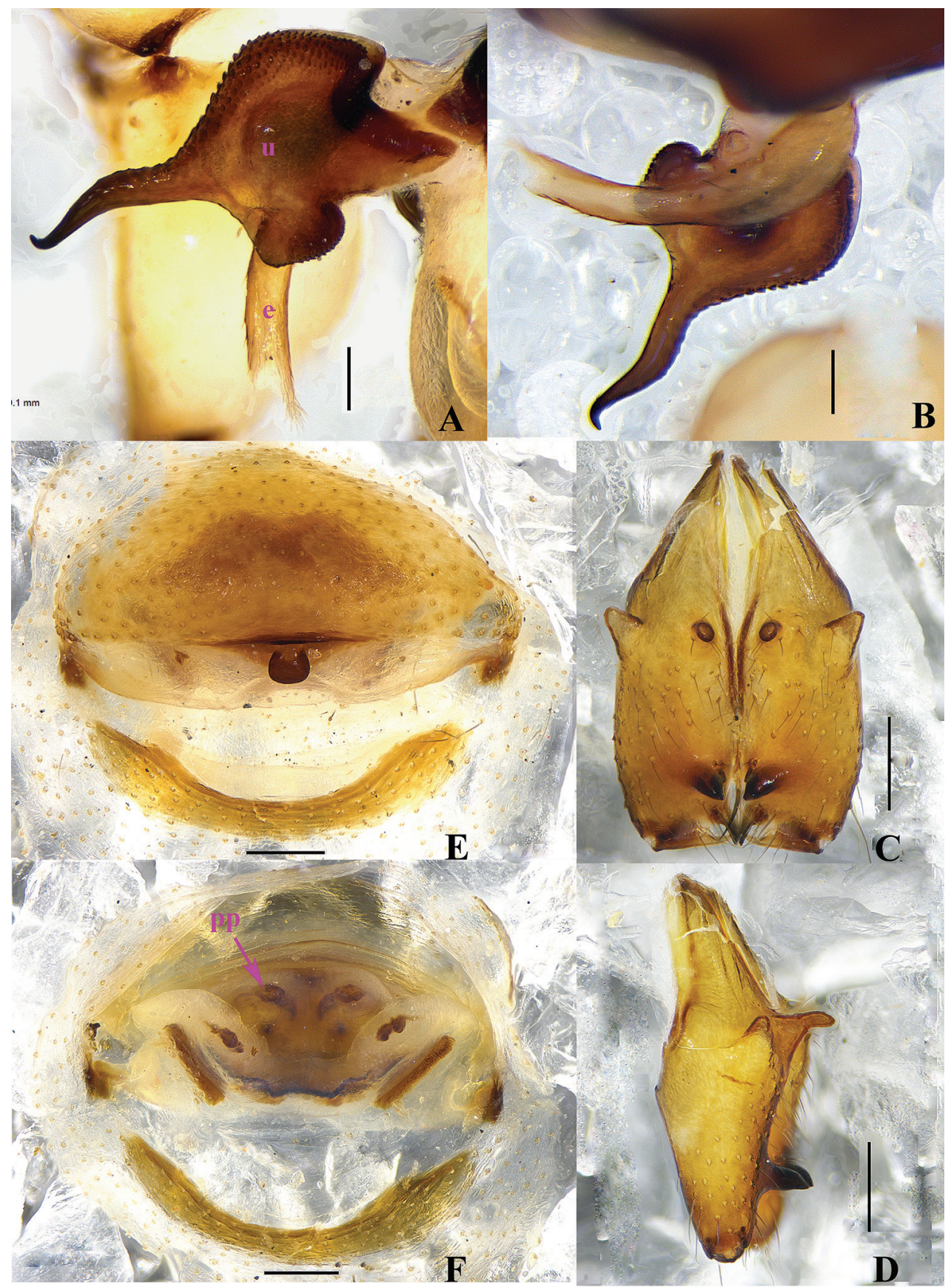

Figure 6. Pholcus curvus sp. n., male holotype (A-D) and female paratype (E-F). A-B Bulb and uncus (A prolateral view B retrolateral view) C-D Chelicerae (C frontal view D lateral view) E Epigynum, ventral view F Vulva, dorsal view. Scale bars: $0.1 \mathrm{~mm}(\mathbf{A}, \mathbf{B}) ; 0.2 \mathrm{~mm}(\mathbf{C}-\mathbf{F})$. 

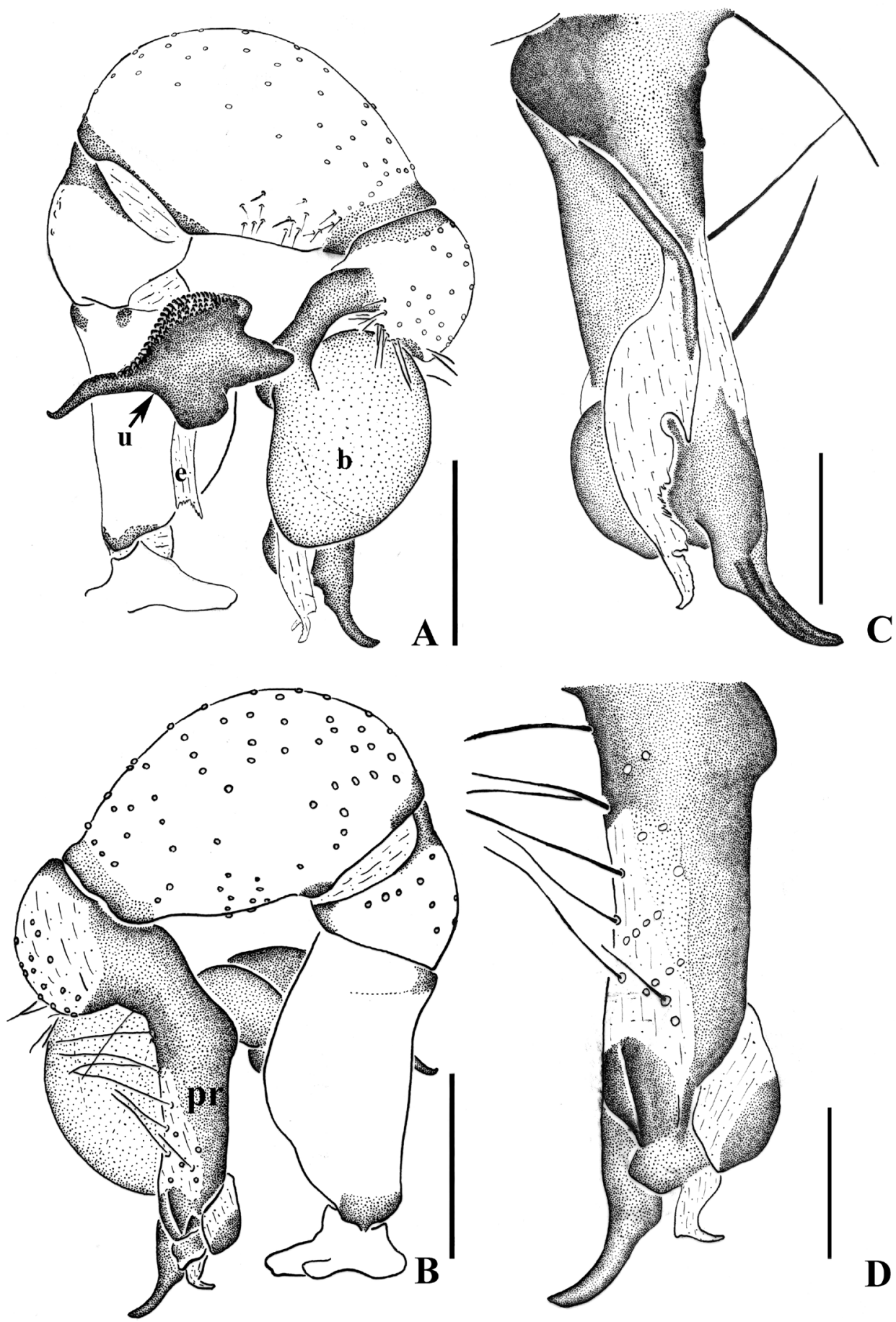

D

Figure 7. Pholcus curvus sp. n., male holotype. A-B Pedipalpus (A prolateral view B retrolateral view) C-D Distal part of procursus (C prolateral view D retrolateral view). Scale bars: $0.2 \mathrm{~mm}$. 

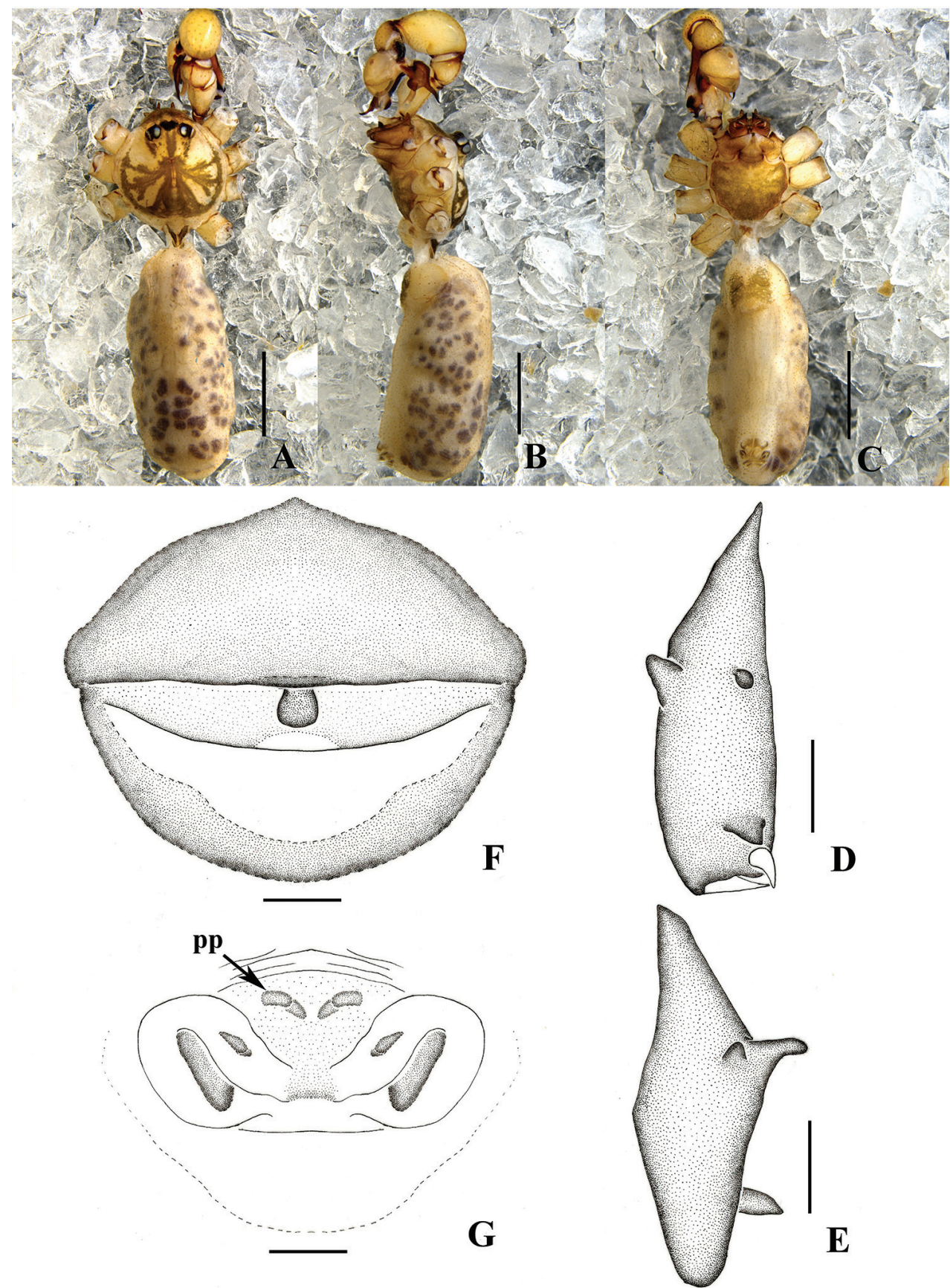

Figure 8. Pholcus curvus sp. n., male holotype (A-E) and female paratype (F-G). A-C Habitus (A dorsal view B lateral view $\mathbf{C}$ ventral view) D-E Chelicerae (D frontal view $\mathbf{E}$ lateral view) $\mathbf{F}$ Epigynum, ventral view G Vulva, dorsal view. Scale bars: $0.2 \mathrm{~mm}(\mathbf{D}-\mathbf{G}) ; 1.0 \mathrm{~mm}(\mathbf{A}-\mathbf{C})$. 
sternum light. Legs long, brown, with two dark brown ring spots on proximal parts of femora and four dark brown ring spots on tibiae. Measurements of legs: I 33.98 (9.57 $+0.53+9.23+13.23+1.42)$, II $24.63(6.96+0.58+6.30+9.49+1.30)$, III 17.75 $(5.22+0.41+4.32+6.79+1.01)$, IV $23.52(6.90+0.47+5.89+9.16+1.10)$; tibia I L/d: 60. Leg formula: 1243. Opisthosoma pale grey, with dark spots dorsally and laterally. Pedipalpi as in Figs 5A-D and 7A-D; trochanter with a moderate ventral apophysis; proximal femur with a small apophysis retrolaterally; tibia with a sheetshaped projection prolaterally; procursus simple and tip with a narrow process, dorsal spines present; uncus long and bent, with a scaly edge; embolus weakly sclerotized.

Female. Generaly similar to the male. One specimens measured: total length 5.09 (5.26 with clypeus), prosoma 1.27 long, 1.52 wide, opisthosoma 3.59 long, 1.61 wide, clypeus 0.20 high. Diameter AME 0.08, ALE 0.10, PME 0.13, PLE 0.12. Distance AME-AME 0.07, AME-ALE 0.07, PME-PME 0.17, PME-PLE 0.05, ALE-ALE 0.45, PLE-PLE 0.59. MOA 0.25 long, front width 0.14 , back width 0.36 . Labium wider than long (0.31/0.17). Sternum wider than long (1.05/0.79). Measurements of legs: I $32.15(7.99+0.55+8.09+13.42+2.10)$, II $20.24(6.31+0.42+5.60+6.55+$ $1.36)$, III $17.40(4.71+0.55+3.87+6.95+1.32)$, IV $20.12(6.03+0.64+5.53+$ $6.55+1.37$ ); tibia I L/d: 50. Leg formula: 1243. Epigynum (Figs 6E and 8F) brown, roughly striped with distinct patterns and an almost quadrate-shaped apophysis on the top. Dorsal view of vulva (Figs 6F and 8G) with a rainbow-shaped, sclerotized arch anteriorly, two bent pore plates, and two long and bent sclerites.

Variation. Male: Total body length: 4.38, 4.43, 4.50. Tibia I $(n=3): 9.36,9.46$, 9.57 (mean: 9.46). Female: Total body length 4.78-5.09. Tibia I $(n=8): 7.65-7.99$ (mean 7.81).

Distribution. Only known from the type locality.

Remarks. Among the P. phungiformes group, the males of the new species resemble $P$. hamatus Tong \& Ji, 2010 by the following: uncus with a narrow, long and bent tip and a robust apophysis, without appendix and pseudo-appendix (Figs 5A, 6A-B, 7A). The females of the new species are distinguished from those of $P$. hamatus by the small and almost quadrate-shaped epigynal apophysis (Figs 6E, 8F).

\section{Pholcus auricularis sp. $\mathbf{n}$.}

http://zoobank.org/294FFD7E-3826-48F3-8E79-A5BC1FA40825

Figs $9-12$

Type material. Holotype: male (MHBU), CHINA: Hebei Province, Fuping County, Longquanguan Town, Liaodaobei Village, $38^{\circ} 16^{\prime} \mathrm{N}, 114^{\circ} 17^{\prime} \mathrm{E}$, alt. $1050 \mathrm{~m}, 5$ August 2014, B.S. Zhang leg. Paratypes: 6 females (MHBU), same data as in holotype.

Etymology. The specific name is from the Latin word "auricularis", in reference to the shape of pedipalpi; adjective. 


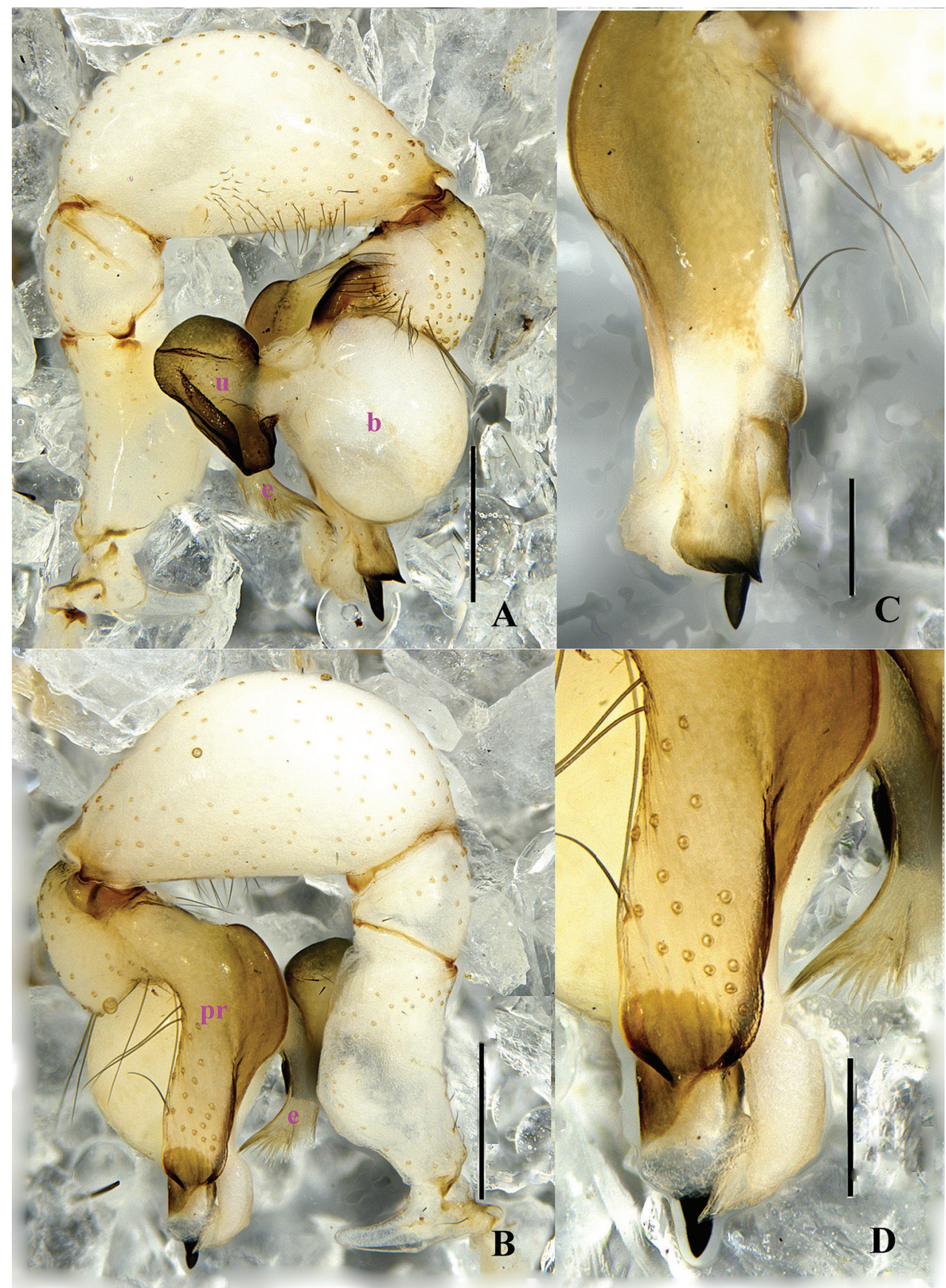

Figure 9. Pholcus auricularis sp. n., male holotype. A-B Pedipalpus (A prolateral view B retrolateral view) C-D Distal part of procursus (C prolateral view $\mathbf{D}$ retrolateral view). Scale bars: $0.2 \mathrm{~mm}(\mathbf{C}, \mathbf{D})$; $0.5 \mathrm{~mm}(\mathbf{A}, \mathbf{B})$. 


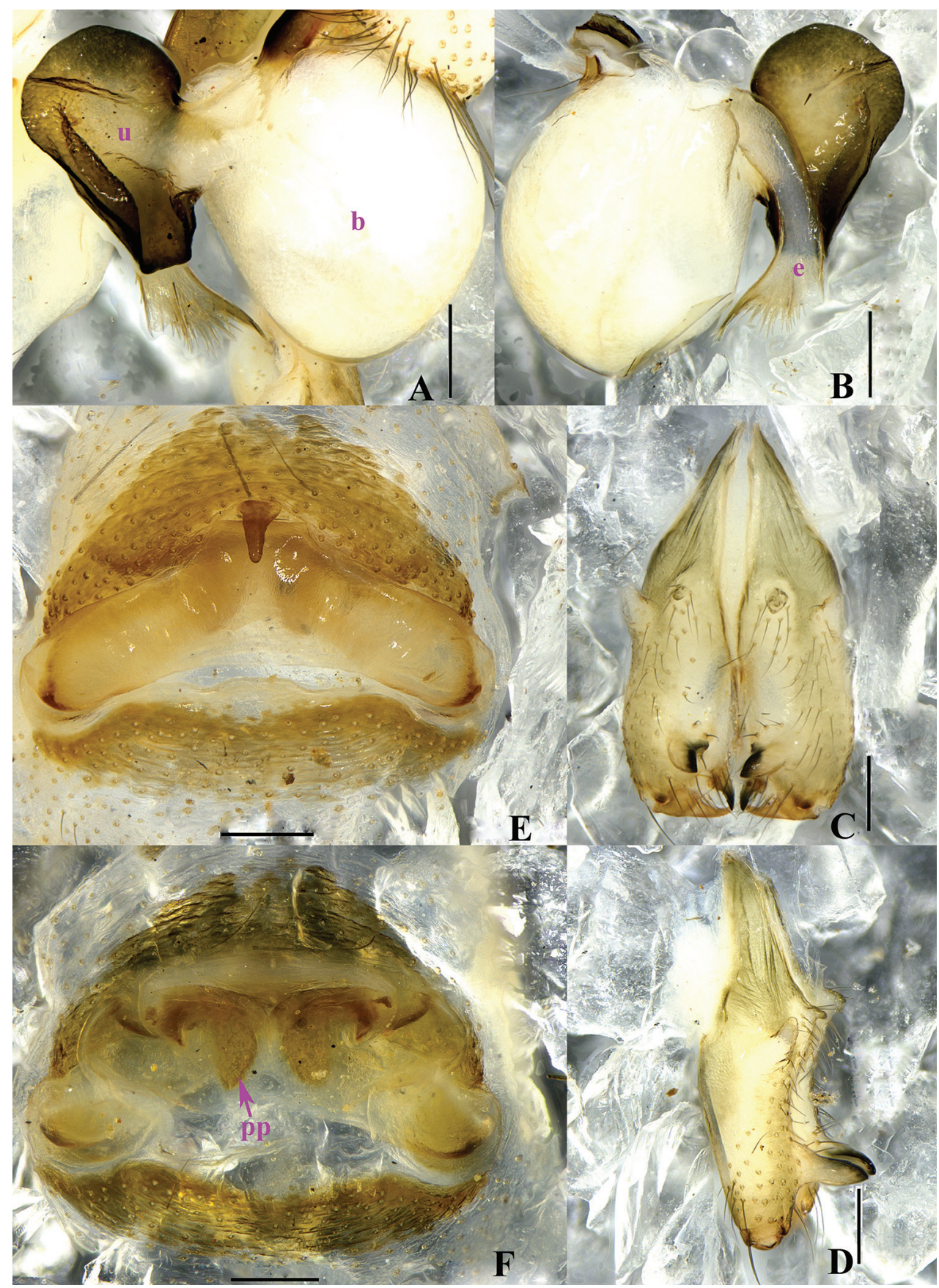

Figure 10. Pholcus auricularis sp. n., male holotype (A-D) and female paratype (E-F) A-B Bulb and uncus (A prolateral view B retrolateral view) C-D Chelicerae (C frontal view D lateral view) E Epigynum, ventral view $\mathbf{F}$ Vulva, dorsal view. Scale bars: $0.2 \mathrm{~mm}$. 

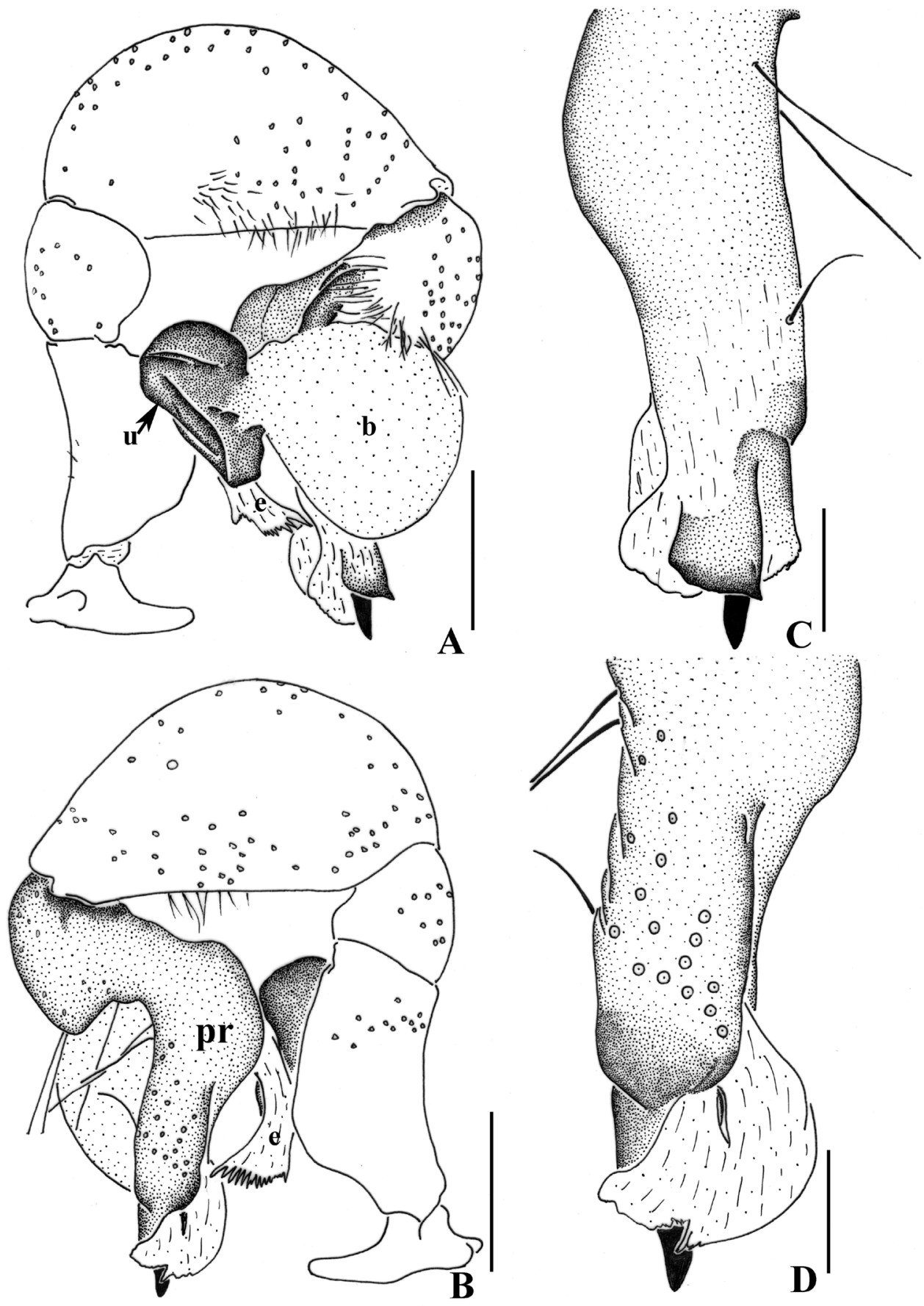

Figure II. Pholcus auricularis sp. n., male holotype. A-B Pedipalpus (A prolateral view B retrolateral view) C-D Distal part of procursus (C prolateral view $\mathbf{D}$ retrolateral view). Scale bars: $0.2 \mathrm{~mm}(\mathbf{C}, \mathbf{D})$; $0.5 \mathrm{~mm}(\mathbf{A}, \mathbf{B})$. 

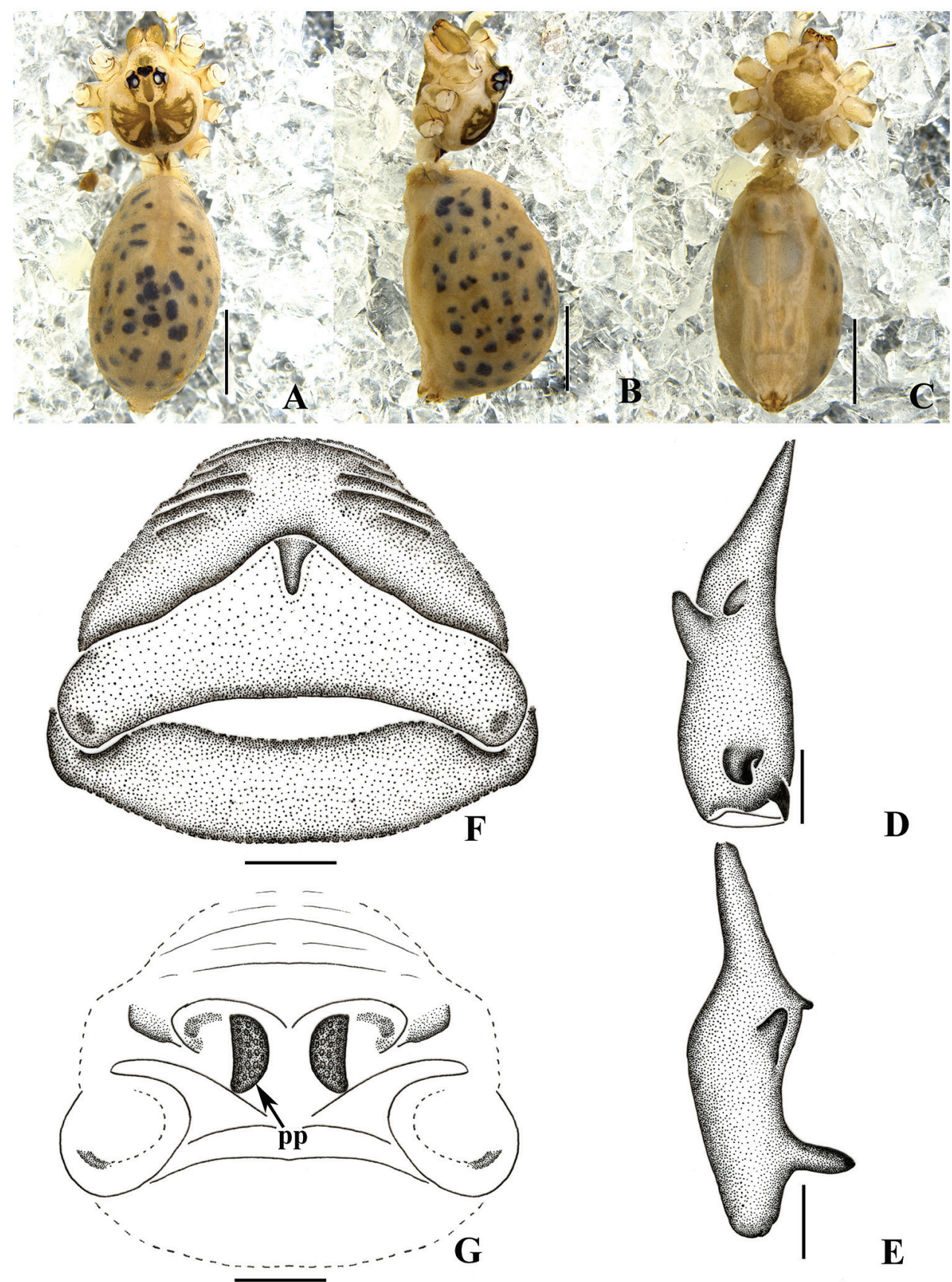

D

$\mathbf{E}$

Figure 12. Pholcus auricularis sp. n., male holotype (A-E) and female paratype (F-G) A-C Habitus (A dorsal view $\mathbf{B}$ lateral view $\mathbf{C}$ ventral view) D-E Chelicerae (D frontal view E lateral view) $\mathbf{F}$ Epigynum, ventral view G Vulva, dorsal view. Scale bars: $0.2 \mathrm{~mm}(\mathbf{D}-\mathbf{G}) ; 1.0 \mathrm{~mm}(\mathbf{A}-\mathbf{C})$. 
Diagnosis. Distinguished by the combination of the following characters: uncus thin, ear-shaped, the tip of procursus thin and extending downward, epigynal apophysis short, thin and clavate, the tip thinner (Figs 9A-D, 10A-B, 10E, 11A-D, 12F).

Description. Male (holotype): Total length 4.13 (5.32 with clypeus), prosoma 1.07 long, 1.19 wide, opisthosoma 2.87 long, 1.54 wide. Habitus as in Figs 12A-C. Dorsal shield of prosoma pale grey, with brown radiated stripes and bands marginally; thoracic groove absent; ocular area elevated, with short eye-stalks; ocular area pale grey, with a wide median brown band and two lateral brown bands beside PLEs, dorsal prosoma and ocular area both with dispersed dark brown spots, of them, two distinct spots behind PMEs; clypeus 0.21 high, pale grey, median part with brown patch. Diameter AME 0.07, ALE 0.10, PME 0.08, PLE 0.09. Distance AME-AME 0.04, AME-ALE 0.06, PME-PME 0.17, PME-PLE 0.06, ALE-ALE 0.47, PLE-PLE 0.54. MOA 0.24 long, front width 0.16, back width 0.35. Chelicerae as in Figs 10C-D and 12D-E, with pair of long apophyses distally and prolateral part black, pair of unsclerotized thumb-shaped apophyses proximolaterally, and pair of nearly nipple-shaped apophyses frontally. Labium and endites brown, distal part pale, labium wider than long $(0.27 / 0.19)$. Sternum wider than long $(0.73 / 0.58)$, brown, median part of sternum light, margin pale grey. Legs long, pale grey, with four brown ring spots on femora and tibiae, one brown ring spot on proximal parts of metatarsi. Measurements of legs: I $21.14(5.61+0.44+5.61+7.87+1.61)$, II $15.13(4.54+0.27+$ $3.75+5.34+1.23)$, III $11.14(3.15+0.34+2.72+3.90+1.03)$, IV $14.89(4.22+0.30+$ $3.69+5.28+1.40)$; tibia I L/d: 51 . Leg formula: 1243 . Opisthosoma pale grey, with dark spots dorsally and laterally. Pedipalpi as in Figs 9A-D and 11A-D; trochanter with a moderate ventral apophysis; tibia with a sheet-shaped projection prolaterally; procursus simple, its tip extending downward, dorsal spines absent; uncus and embolus weakly sclerotized.

Female. Similar to male. One specimen measured: total length 4.95 (5.12 with clypeus), prosoma 1.35 long, 1.48 wide, opisthosoma 3.42 long, 2.35 wide. clypeus 0.22 high, yellow. Diameter AME 0.04, ALE 0.10, PME 0.10, PLE 0.12. Distance AME-AME 0.07, AME-ALE 0.06, PME-PME 0.23, PME-PLE 0.06, ALE-ALE 0.50, PLE-PLE 0.61. MOA 0.21 long, front width 0.19 , back width 0.37 . Labium wider than long $(0.27 / 0.18)$. Sternum wider than long $(0.97 / 0.75)$. Measurements of legs: I $21.82(7.00+0.56+5.59$ $+7.42+1.25)$, II $18.03(5.23+0.55+4.57+6.53+1.15)$, III $13.44(3.80+0.39+3.31$ $+4.91+1.03)$, IV $17.74(4.86+0.52+4.48+6.69+1.19)$; tibia I L/d: 63. Leg formula: 1243. Epigynum (Figs $10 \mathrm{E}$ and $12 \mathrm{~F}$ ) brown, roughly triangular, with distinct patterns and a short rod-like apophysis on the top. Dorsal view of vulva (Figs 10F and 12G) with an Mshaped, sclerotized arch anteriorly, two closely spaced semilunar pore plates.

Variation. Female: Total body length 4.68-4.95. Tibia I $(n=6): 6.56-7.00$ (mean 6.86).

Distribution. Only known from the type locality.

Remarks. Among the $P$. phungiformes group, the new species resembles $P$. alloctospilus Zhu \& Gong, 1991 and $P$. fengchen Zhang \& Zhu, 2009, but can be distinguished from those by: the short and thick club-shaped projection on tip of procursus, chitinized plate of the epigynum triangular arch (Figs 9C-D, 10E, 11C-D, 12F). 


\section{Conclusions}

The P. phungiformes group includes 52 nominal species, of which 33 species were recorded from China (Zhang and Zhu 2009; Tong and Ji 2010; Tong and Li 2010; Huber 2011b; Chen, Zhang and Zhu 2011; Yao and Li 2012; Peng and Zhang 2013; Seo 2014; Liu and Tong 2015). Most of these chinese species are distributed in northeastern China: from Hebei Province P. alloctospilus, P. pennatus, P. zhuolu, P. triangulates, P. wangxidong, P. chicheng, P. datan, P. babao, P. wuling, P. jinniu, P. exilis, P. papillatus sp. n., $P$. curvus sp. n. and $P$. auricularis sp. n. are known, from Beijing municipality $P$. beijingensis, $P$. brevis, from Liaoning Province P. suizhongicus, $P$. jiuwei, P. fengcheng, P. phoenixus, $P$ gaoi, $P$. wangtian, $P$. tongi, $P$. wangi, $P$. decorus, $P$. hamatus, $P$. lingulatus, $P$. foliaceus, $P$. xianrendong and $P$. sublingulatus, from Shanxi Province $P$. luya, and from both Hebei and Liaoning Provinces P. clavimaculatus, only $P$. xingren occurs in Guizhou Province.

\section{Acknowledgements}

We are grateful to an anonymous referee, Professor Shuqiang Li and Professor Nathalie Yonow for valuable suggestions. Professor Malcolm Lyon (The University of Manchester, the UK) kindly helped in reviewing the English of the manuscript. This study was supported by the Postdoctoral Science Foundation of China (No. 2014M551043) and partially by the National Natural Science Foundation of China (No. 31471969).

\section{References}

Chen HM, Zhang F, Zhu MS (2011) Four new troglophilous species of the genus Pholcus Walckenaer (Araneae, Pholcidae) from Guizhou province, China. Zootaxa 2922: 51-59.

Dimitrov D, Ribera C (2007) The genus Pholcus (Araneae, Pholcidae) in the Canary Islands. Zoological Journal of the Linnean Society 151: 59-114. doi: 10.1111/j.10963642.2007.00316.x

Dimitrov D, Arnedo MA, Ribera C (2008) Colonization and diversification of the spider genus Pholcus Walckenaer, 1805 (Araneae, Pholcidae) in the Macaronesian archipelagos: Evidence for long-term occupancy yet rapid recent speciation. Molecular Phylogenetics and Evolution 48: 596-614. doi: 10.1016/j.ympev.2008.04.027

Huber BA (2011a) Phylogeny and classification of Pholcidae (Araneae): an update. Journal of Arachnology 39: 211-222. doi: 10.1636/CA10-57.1

Huber BA (2011b) Revision and cladistic analysis of Pholcus and closely related taxa (Araneae, Pholcidae). Bonner Zoologische Monographien 58: 1-509.

Huber BA (2000) New World pholcid spiders (Araneae: Pholcidae): A revision at generic level. Bulletin of the American Museum of Natural History 254: 1-348. doi: 10.1206/0003-00 90(2000)254<0001:NWPSAP>2.0.CO;2 
Huber BA (2001) The pholcids of Australia (Araneae; Pholcidae): taxonomy, biogeography, and relationships. Bulletin of the American Museum of Natural History 260: 1-144. doi: 10.1206/0003-0090(2001)260<0001:TPOAAP>2.0.CO;2

Huber BA (2003a) Cladistic analysis of Malagasy pholcid spiders reveals generic level endemism: Revision of Zatavua n. gen. and Paramicromerys Millot (Pholcidae, Araneae). Zoological Journal of the Linnean Society 137: 261-318. doi: 10.1046/j.1096-3642.2003.00046.x

Huber BA (2003b) High species diversity in one of the dominant groups of spiders in East African montane forests (Araneae: Pholcidae: Buitinga n. gen., Spermophora Hentz). Zoological Journal of the Linnean Society 137: 555-619. doi: 10.1046/j.1096-3642.2003.00053.x

Huber BA (2003c) Southern African pholcid spiders: revision and cladistic analysis of Quamtana gen. nov. and Spermophora Hentz (Araneae: Pholcidae), with notes on male-female covariation. Zoological Journal of the Linnean Society 139: 477-527. doi: 10.1046/j.00244082.2003.00082.x

Huber BA (2005a) The pholcid spiders of Africa (Araneae: Pholcidae): state of knowledge and directions for future research. In: Huber BA, Sinclair BJ, Lampe K-H (Eds) African Biodiversity: Molecules, Organisms, Ecosystems. Springer Verlag, the Netherlands, 181-186. doi: 10.1007/0-387-24320-8_15

Huber BA (2005b) High species diversity, male-female coevolution, and metaphyly in Southeast Asian pholcid spiders: the case of Belisana Thorell, 1898 (Araneae, Pholcidae). Zoologica 155: 1-126.

Huber BA (2005c) Revision of the genus Spermophora Hentz in Southeast Asia and on the Pacific islands, with descriptions of three new genera (Araneae: Pholcidae). Zoologische Mededelingen (Leiden) 79: 61-114.

Huber BA (2009a) Four new generic and 14 new specific synonymies in Pholcidae, and transfer of Pholcoides Roewer to Filistatidae (Araneae). Zootaxa 1970: 64-68. [plus Erratum, Zootaxa 1977: 68]

Huber BA (2009b) Life on leaves: leaf-dwelling pholcids of Guinea, with emphasis on Crossopriza cylindrogaster, a spider with inverted resting position, pseudo-eyes, lampshade web, and tetrahedral egg-sac (Araneae: Pholcidae). Journal of Natural History 43: 2491-2523. doi: 10.1080/00222930903207876

Liu Y, Tong YF (2015) A new species of the genus Pholcus Walckenaer, 1805 from Xianrendong National Forest Park, Liaoning Province, China (Araneae: Pholcidae). Acta Arachnologica Sinica 24(1): 31-34.

Peng Y, Zhang F (2011a) A new species of the genus Pholcus Walckenaer, 1805 (Araneae, Pholcidae) from Hainan Island, China. ISRN Zoology 2011: 1-3. doi: 10.5402/2011/345606

Peng Y, Zhang F (2011b) Two new species of the genus Pholcus (Araneae: Pholcidae) from Taihang Mountains, China, with first report of the female of Pholcus oculosus. Entomologica Fennica 22: 78-84.

Peng YQ, Zhang F (2013) Two new Pholcus species from northern China (Araneae: Pholcidae). Acta Arachnologica (Tokyo) 62(2): 75-80. doi: 10.2476/asjaa.62.75

Seo BK (2014) Four new species of the genus Pholcus (Araneae: Pholcidae) from Korea. Korean Journal of Applied Entomology 53(4): 399-408. doi: 10.5656/KSAE.2014.10.0.059 
Tong YF, Ji L (2010) Three new species of the spider genus Pholcus (Araneae: Pholcidae) from Liaodong Mountain, China. Entomologica Fennica 21: 97-103.

Tong YF, Li SQ (2010) Eight new spider species of the genus Pholcus (Araneae, Pholcidae) from China. Zootaxa 2355: 35-55.

World Spider Catalog (2016) World Spider Catalog. Natural History Museum Bern. http:// wsc.nmbe.ch, version 17.0 [accessed 22 January 2016]

Yao ZY, Pham DS, Li SQ (2015) Pholcid spiders (Araneae: Pholcidae) from northern Vietnam, with descriptions of nineteen new species. Zootaxa 3909(1): 1-82. doi: 10.11646/ zootaxa.3909.1.1

Yao ZY, Li SQ (2012) New species of the spider genus Pholcus (Araneae: Pholcidae) from China. Zootaxa 3289: 1-271.

Yao ZY, Li SQ (2013) New and little known pholcid spiders (Araneae: Pholcidae) from Laos. Zootaxa 3709: 1-51. doi: 10.11646/zootaxa.3709.1.1

Zhang F, Zhu M (2009) A review of the genus Pholcus (Araneae: Pholcidae) from China. Zootaxa 2037: 1-114. 